\title{
Correction to: Chapter 8 Encountering Traditional Medicine in Global Health Service
}

\author{
Alexia C. Croteau-Chonka
}

\section{Correction to: \\ References in chapter had been linked incorrectly and the same has now been corrected as below.}

1. The quote from Stephanie Espinosa in Pg. 103 has been linked to the two footnotes that are included in the "Suggested Reading" section as:

"...transforming by themselves. - Stéphane Espinosa [28] [29]"

2. The two references in the "Suggested Reading" section in Pg. 117 has been moved into the "References" section and renumbered to match the footnotes that was given at the end of the quote in the beginning of the chapter. Both the corrections has been updated in chapter. 